Review began 10/28/2021 Review ended 11/11/2021 Published 11/18/2021

๑) Copyright 2021

Thomas et al. This is an open access article distributed under the terms of the Creative Commons Attribution License CC-BY 4.0. which permits unrestricted use, distribution, and reproduction in any medium, provided the original author and source are credited.

\section{Pneumoperitoneum in Rectal Polyembolokoilamania}

\author{
Joel Thomas ${ }^{1}$, Sagar Maheshwari ${ }^{1}$, Ahmed Sallam ${ }^{2}$ \\ 1. Radiology, Barking, Havering and Redbridge University Hospitals NHS Trust, London, GBR 2. Internal Medicine, \\ Leicester Royal Infirmary, Leicester, GBR
}

Corresponding author: Joel Thomas, tjoeljoy@gmail.com

\begin{abstract}
Foreign body insertion in the rectum is not a very common presentation in the emergency department but this is common among individuals with a history of self-harm, personality disorders, and other psychosomatic illnesses. It is often diagnosed on abdominal x-rays; however, a CT scan of the abdomen and pelvis may be warranted when perforation is suspected. To diagnose an anorectal foreign body, clinicians must maintain a high level of suspicion. Because of embarrassment or maybe psychological concerns, the patient may not be ready to share all the information. Healthcare providers must hence show empathy and compassion while being calm and non-judgmental. Here, we present a case of an 80-year-old male who underwent a laparotomy for removal of a large foreign body that was inserted in the rectum and caused a gastrointestinal perforation.
\end{abstract}

Categories: Psychiatry, Radiology, General Surgery

Keywords: psychiatry, pestle, foreign body insertion, rectal polyembolokoilamania, pneumoperitoneum

\section{Introduction}

Anorectal damage caused by foreign body (FB) insertion has been documented since the 1500s. Since then, there have been many reports in the literature of various objects being pushed into the anus. A wide variety of objects self-inserted into the urinary tract have been reported and that includes electrical wires, batteries, glass, pencils, chopsticks, and telephone cables as opposed to anorectal objects documented such as lightbulbs, sex toys, toothbrushes, drugs, cell phones, fruits, vegetables, and in one incidence a frozen pig's tail [1-8]. Fear of social embracement may force a patient to procrastinate medical assessment and therapy, thereby leading to complicating management protocols. As a result, we emphasize the necessity of a high level of suspicion, as well as a thorough and extensive evaluation, followed by a patient-specific strategy through this case report.

\section{Case Presentation}

An 80-year-old male patient presented to the accident and emergency department (A\&E) with sudden acute abdominal pain, distension, and confusion. No surgical scars were noted on his abdomen and his abdomen was clinically distended. He had no past medical history correlating to his presentation. The patient was hemodynamically stable and was admitted to the hospital for further investigations. The role of psychological factors was not considered at this moment, as he shared no past medical history of the same. At this stage, we clinically suspected intestinal obstruction, perforation, or pancreatitis. Upon doing a CT abdo-pelvis later, a pestle-like object was found in the rectum causing perforation. He later admitted that he fantasizes putting objects into his body orifices, and had been diagnosed with polyembolokoilamania before. He initially developed the habit of inserting small objects and then proceeded to try out bigger objects with time.

An initial abdominal x-ray confirmed the presence of a large foreign body in rectum (Figure 1). An urgent abdominal ultrasonography performed showed gaseous abdomen, suspecting free air, but it was inconclusive due to reverberation artifacts. CT abdomen done thereafter revealed an oblong cylindrical shaped object in the rectum causing proximal colon dilatation and rectal perforation, along with free fluid collection. Various signs of pneumoperitoneum, such as the falciform ligament sign, were noted on the CT (Figures 2, 3). 


\section{Cureus}

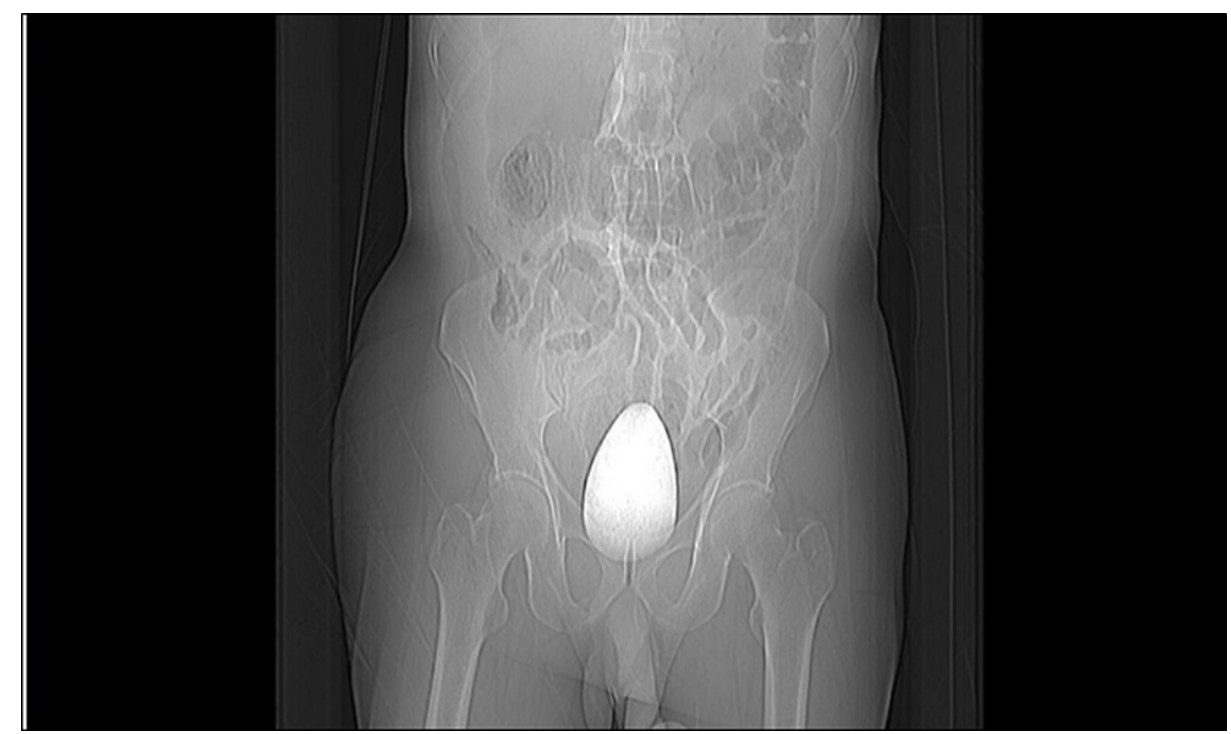

FIGURE 1: Abdominal $x$-ray showing the presence of a large foreign body in rectum.

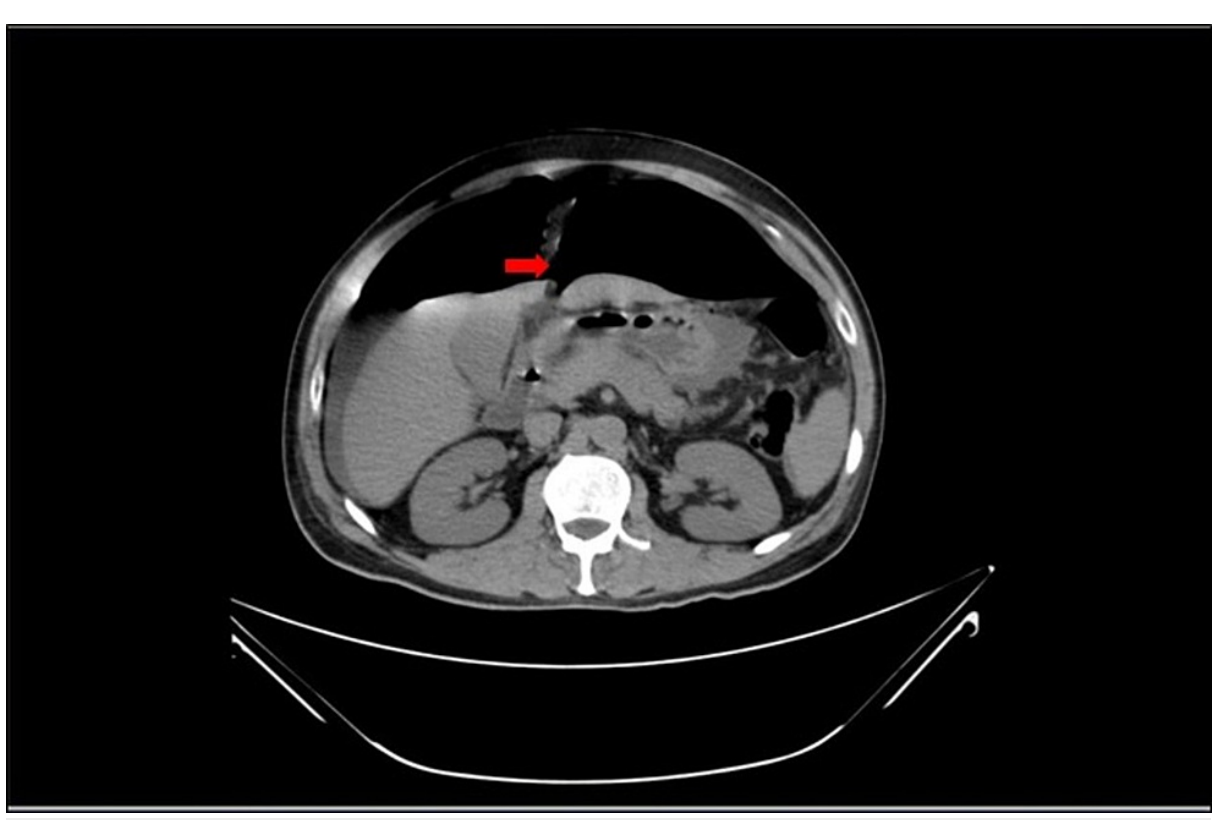

FIGURE 2: CT abdomen - transverse view showing falciform ligament sign. 


\section{Cureus}

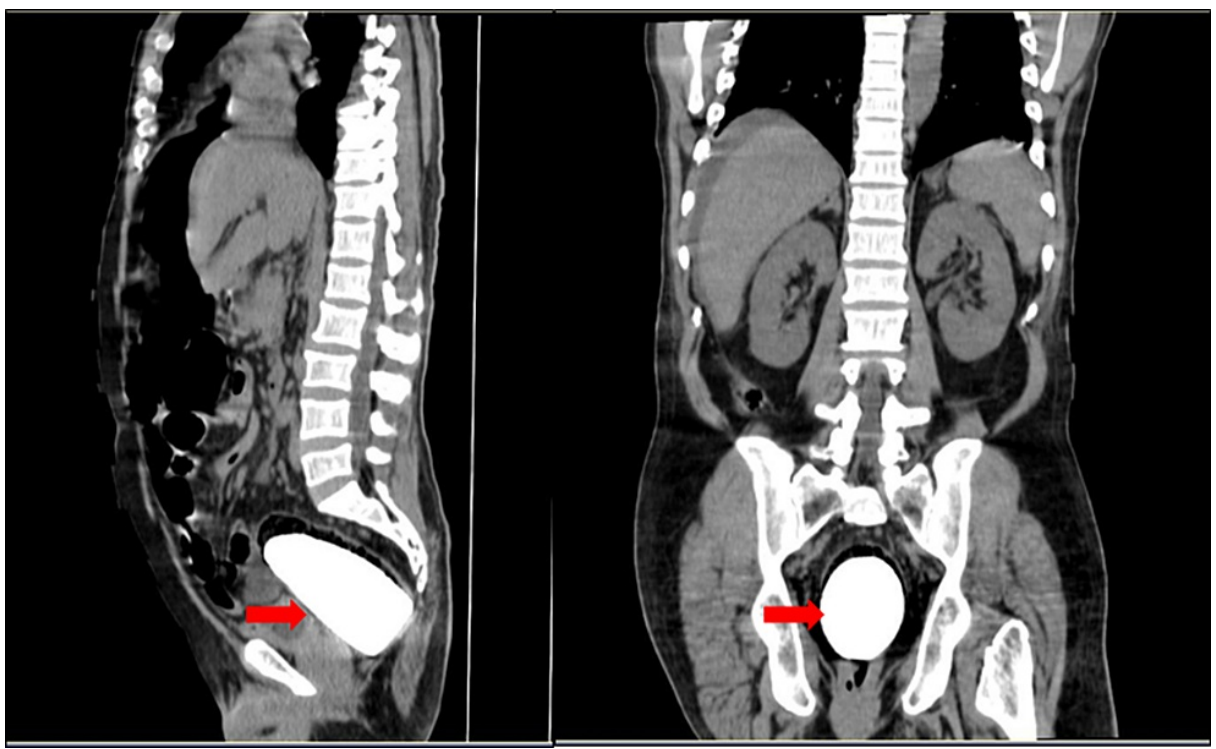

FIGURE 3: CT abdomen - sagittal and coronal views demonstrating what looks like a "pestle" in the rectum.

The patient underwent a surgical laparotomy to remove the object, where it was then confirmed that it was a ceramic pestle. The patient recovered after surgery from acute abdominal perforation and was transferred for care under the psychiatry team.

\section{Discussion}

Polyembolokoilamania represents a broad group of disorders characterized by the self-insertion of objects into body orifices caused by a number of psychosocial and psychological conditions. It is common in people who have a history of self-harm, personality disorders, schizophrenia, or alcoholism, as well as in prison inmates [9]. Adults who insert foreign objects, and often suffer from mental illness, have residual curiosities that manifest as experimentation, attempts to rekindle past memories or relationships, or do so to increase sexual arousal which is the most common motive $[10,11]$. The majority of patients present after attempting to remove the object at home but failing or when it has caused perforation. Patients frequently give vague history as it was with this case. The situation is further complicated by the delayed presentation, which is sometimes due to embarrassment, or the varied presentations of the numerous items of various sizes and shapes that find their way into one's rectum $[9,12]$. In patients presenting with acute abdominal pain with or without psychiatric history, foreign bodies should always be part of the differential diagnosis. Rectal foreign bodies can be detected by either x-rays or CTs. If perforation is ever suspected, in cases like peritonitis or shock, CT should be done, preferably with rectal contrast or rectal enema with water-soluble contrast to detect the level of the perforation. No attempts at bedside extraction should be made if peritonitis is present or if the patient is unstable, instead, the patient should be moved to the operating room for an emergent laparotomy. Prior to surgery, intravenous fluids and antibiotics should be administered. If a perforation is suspected, the presence of pneumoperitoneum on a clear abdominal film can quickly validate the diagnosis and speed up the decision to operate. In the vast majority of patients, however, these signs may not be present and a less invasive method can be attempted [13].

\section{Conclusions}

One should always keep a high index of suspicion of the psychological factors that may have an indirect role in acute abdomen presentations, through the insertion of foreign bodies, even when there is no clear history of any psychiatric illness. In most cases, plain abdominal x-ray may be sufficient, but in cases where perforation is suspected, computed tomography is preferred. Various treatment options such as manual evacuation of foreign body, sigmoidoscopic removal, or laparotomy may be considered on a case-to-case basis. A detailed psychiatric evaluation is also warranted after the surgical management.

\section{Additional Information}

\section{Disclosures}

Human subjects: Consent was obtained or waived by all participants in this study. Conflicts of interest: In compliance with the ICMJE uniform disclosure form, all authors declare the following: Payment/services info: All authors have declared that no financial support was received from any organization for the submitted work. Financial relationships: All authors have declared that they have no financial 
relationships at present or within the previous three years with any organizations that might have an interest in the submitted work. Other relationships: All authors have declared that there are no other relationships or activities that could appear to have influenced the submitted work.

\section{References}

1. Gould GM, Pyle WL: Anomalies and Curiosities of Medicine: Being an Encyclopedic Collection of Rare and Extraordinary Cases, and of the Most Striking Instances of Abnormality in All Branches of Medicine and Surgery, Derived From an Exhaustive Research of Medical Literature From Its Origin to the Present Day: Abstracted, Classified, Annotated, and Indexed. W.B. Saunders, Philadelphia, PA; 1897. http://resource.nlm.nih.gov/57221200R.

2. Sharif M, Alizargar J: Self-insertion of a screwdriver into the rectum for sexual pleasure: a case report . Australas J Paramedicine. 2013, 10:10.33151/ajp.10.1.47

3. Bantis A, Sountoulides P, Kalaitzis C, Giannakopoulos S, Agelonidou E, Foutzitzi S, Touloupidis S: Perforation of the urinary bladder caused by transurethral insertion of a pencil for the purpose of masturbation in a 29-year-old female. Case Rep Med. 2010, 2010: 10.1155/2010/460385

4. Bedi N, El-Husseiny T, Buchholz N, Masood J: 'Putting lead in your pencil': self-insertion of an unusual urethral foreign body for sexual gratification. JRSM Short Rep. 2010, 1:1-5. 10.1258/shorts.2010.010014

5. Hwang EC, Kim JS, Jung SI, et al.: Delayed diagnosis of an intraurethral foreign body causing urosepsis and penile necrosis. Korean J Urol. 2010, 51:149-51. 10.4111/kju.2010.51.2.149

6. Moon SJ, Kim DH, Chung JH, Jo JK, Son YW, Choi HY, Moon HS: Unusual foreign bodies in the urinary bladder and urethra due to autoerotism. Int Neurourol J. 2010, 14:186-9. 10.5213/inj.2010.14.3.186

7. Stravodimos KG, Koritsiadis G, Koutalellis G: Electrical wire as a foreign body in a male urethra: a case report. J Med Case Rep. 2009, 3: 10.1186/1752-1947-3-49

8. Trehan RK, Haroon A, Memon S, Turner D: Successful removal of a telephone cable, a foreign body through the urethra into the bladder: a case report. J Med Case Rep. 2007, 1: 10.1186/1752-1947-1-153

9. Dunphy L, Syed F, Raja M: Foreign bodies in the abdomen: self-harm and personality disorders . BMJ Case Rep. 2015, 2015:10.1136/bcr-2015-209954

10. Unruh BT, Nejad SH, Stern TW, Stern TA: Insertion of foreign bodies (polyembolokoilamania): underpinnings and management strategies. Prim Care Companion CNS Disord. 2012, 14:10.4088/PCC.11f01192

11. Hunter TB, Taljanovic MS: Foreign bodies. Radiographics. 2003, 23:731-57. 10.1148/rg.233025137

12. Gupta SS, Singh O, Hastir A, Shukla S, Mathur RK: Foreign bodies in the rectum: a report on three cases including a bullhorn in the rectum. Arab J Gastroenterol. 2010, 11:108-12. 10.1016/j.ajg.2010.03.002

13. Cologne KG, Ault GT: Rectal foreign bodies: what is the current standard? . Clin Colon Rectal Surg. 2012, 25:214-8. 10.1055/s-0032-1329392 